\title{
Organofosforados e organoclorados: toxicologia médica e reflexos ambientais
}

\author{
Organophosphorus and organochlorines: medical toxicology and environmental reflexes
}

Organofosforados y organoclorados: toxicología médica y reflejos medioambientales

\section{Resumo}

Os pesticidas ou agrotóxicos são substâncias químicas utilizadas na agricultura, por possuir atividade sobre inúmeros organismos vivos prejudiciais às culturas. Neste âmbito, os compostos organofosforados e organoclorados apresentam grande relevância, devido a quadros de intoxicação humana de importância médica e contaminação ambiental. O objetivo deste trabalho é realizar uma sistematização de informações, contextualizando a problemática de forma crítica com ênfase na ecotoxicologia e seus reflexos médicos, associados ao uso de compostos organofosforados e organoclorados. Para tanto, realizou-se uma revisão bibliográfica narrativa, delineada pela busca de artigos científicos e bibliografias sobre tais compostos nos principais repositórios eletrônicos internacionais. Os descritores utilizados para busca foram: pesticidas, agrotóxicos, organoclorados, organofosforados, toxicidade, diagnóstico, tratamento e impacto ambiental. O diagnóstico é majoritariamente clínico, porém, análises laboratoriais para avaliação/diagnóstico podem ser realizadas, como a determinação de atividade da colinesterase eritrocitária (AChE) e colinesterase plasmática (BChE), para fins de prognóstico/monitoramento em casos crônicos. Outros exames também podem ser solicitados para análise e investigação. O protocolo terapêutico seguido em casos de intoxicação por organofosforados constitui-se na administração de drogas com atividade antagonista às substâncias, como a atropina e as oximas, carvão ativado, drogas anticonvulsivantes/neuroprotetoras e cuidados intensivos quando necessários. Entretanto, não há nenhum tipo de tratamento definitivo relacionado à toxicidade por organoclorados. Apesar de possuir grande toxicidade ambiental e às formas de vida, os compostos organofosforados continuam sendo utilizados para o combate a pragas agrícolas, enquanto os organoclorados para o controle vetorial/disseminação de doenças. Ademais, tais compostos estão associados a acidentes ocupacionais e também a suicídios.

Palavras-chave: Pesticidas; Agrotóxicos; Organoclorados; Organofosforados; Toxicidade; Diagnóstico; Tratamento; Impacto ambiental.

\begin{abstract}
Pesticides or agrochemicals are chemical substances used in agriculture, because they have activity on countless living organisms that are harmful to crops. In this context, the organophosphorus and organochlorine compounds are of great relevance, due to the human intoxication of medical importance and environmental contamination. The objective of this work is to systematize information, contextualizing the problem in a critical way with emphasis on ecotoxicology and it's medical consequences, associated with the use of organophosphorus and organochlorine compounds. To this end, a narrative literature review was conducted, outlined by searching for scientific articles and bibliographies about such compounds in the main international electronic repositories. The descriptors used for the search were: pesticides, agrochemicals, organochlorines, organophosphorus, toxicity, diagnosis, treatment, and environmental impact. Diagnosis is mostly clinical, but laboratory tests for evaluation/diagnosis can be performed, such as determination of erythrocyte cholinesterase (AChE) activity and plasma cholinesterase (BChE), for prognostic/monitoring purposes in chronic cases. Other tests may also be requested for analysis and investigation. The therapeutic protocol in cases of organophosphate intoxication consists of the administration of drugs with antagonistic activity to the substances, such as atropine and oximes, activated charcoal, anticonvulsant/neuroprotective drugs, and intensive care when necessary. However, there is no definitive treatment for organochlorine toxicity. Despite their high toxicity to the environment and to life forms, organophosphate compounds continue to be used for agricultural pest control, while organochlorines are used for vector control/disease dissemination. Moreover, such compounds are associated with occupational accidents and suicide.
\end{abstract}

Keywords: Pesticides; Agrochemicals; Organochlorines; Organophosphorus; Toxicity; Diagnosis; Treatment; Environmental impact. 


\begin{abstract}
Resumen
Los plaguicidas o agroquímicos son sustancias químicas utilizadas en la agricultura, por poseer actividad sobre innumerables organismos vivos perjudiciales para los cultivos. En este contexto, los compuestos organofosforados y organoclorados son de gran relevancia, debido a cuadros de intoxicación humana de importancia médica y contaminación ambiental. El objetivo de este trabajo es sistematizar la información, contextualizando el problema de forma crítica con énfasis en la ecotoxicología y sus consecuencias médicas, asociadas al uso de compuestos organofosforados y organoclorados. Para ello, se llevó a cabo una revisión bibliográfica narrativa, esbozada mediante la búsqueda de artículos científicos y bibliográficos sobre dichos compuestos en los principales repositorios electrónicos internacionales. Los descriptores utilizados para la búsqueda fueron: plaguicidas, agroquímicos, organoclorados, organofosforados, toxicidad, diagnóstico, tratamiento y impacto ambiental. El diagnóstico es principalmente clínico, pero pueden realizarse pruebas laboratoriales para la evaluación/diagnóstico, como la determinación de actividad de la colinesterasa eritrocitaria (AChE) y colinesterasa plasmática (BChE) con fines de prognóstico/seguimiento en casos crónicos. También se pueden solicitar otras pruebas para análisis y investigación. El protocolo terapéutico en casos de intoxicación por organofosforados consiste en la administración de fármacos con actividad antagonista a las sustancias, como atropina y oximas, carbón activado, fármacos anticonvulsivos/neuroprotectores y cuidados intensivos cuando necesario. Sin embargo, no existe tratamiento definitivo relacionado con la toxicidad por organoclorados. A pesar de su elevada toxicidad para el medio ambiente y las formas de vida, los compuestos organofosforados siguen utilizándose para combatir las plagas agrícolas, mientras que los organoclorados se emplean para el control de vectores y diseminación de enfermedades. Además, estos compuestos están asociados a los accidentes laborales y también a suicidios.
\end{abstract}

Palabras clave: Plaguicidas; Agroquímicos; Organoclorados; Organofosforados; Toxicidad; Diagnóstico; Tratamiento; Impacto ambiental.

\title{
1. Introdução
}

Os agrotóxicos, também designados como pesticidas, são substâncias químicas utilizadas em amplo espectro para controle/inibição da ação de insetos, fungos, ervas daninhas e outros agentes que possam ser prejudiciais para a agricultura, devido à sua atividade sobre organismos vivos (Baptista, 1999). Com o crescimento populacional e má distribuição de renda há demanda constante de aumento na produção alimentícia, resultando na elevação e intensificação do uso de agentes físicos, químicos e biológicos nestas culturas. Assim, muitas vezes, este uso ocorre de forma indiscriminada para que a produção, sobretudo monocultural e em grande quantidade, mantenha-se em ritmo contínuo. No Brasil, a agricultura é um dos principais pilares econômicos, havendo assim o uso de pesticidas em larga escala. As classes mais utilizadas em território nacional são os herbicidas (44,0\%), seguido pelos inseticidas (19,8\%) e fungicidas (16,1\%) (Botelho et al., 2020). Entretanto, estes compostos são tóxicos aos insetos e outros organismos vivos, trazendo risco à saúde humana. Ademais, os agrotóxicos geram impacto nos ecossistemas, por permanecerem ativos no meio ambiente por longos períodos.

Tais agentes químicos podem atingir o solo através do contato direto com a superfície ou por meio do tratamento de sementes. A chegada destes ao solo pode também ocorrer de forma indireta, através da pulverização dos pesticidas em frutos e folhas, que posteriormente possam vir ao chão. Uma vez no solo, estes compostos podem carreados pela água das chuvas, atingindo rios e lagos, além de poderem percolar e chegar aos lençóis freáticos (Santos, 2002; Teixeira et al., 2004). Assim, a poluição antropogênica do meio ambiente afeta as formas de vida vegetais, animais e, concomitantemente, influencia a saúde humana.

De maneira geral, os pesticidas podem ser classificados de acordo com sua estrutura química, respectivamente em orgânicos ou inorgânicos. Os compostos orgânicos possuem cadeias carbônicas e podem ser divididos conforme sua composição química, respectivamente: carbamatos, organofosforados, organoclorados, piretrinas e piretróides. Em contrapartida, os compostos inorgânicos são aqueles que não apresentam nenhum átomo de carbono em sua estrutura, sendo classificados por sua vez em miscelânea, fluorados e arsenicais, sendo muito pouco utilizados devido à elevada toxicidade, grande impacto ao meio ambiente e baixa eficiência contra pragas (Oga, 2003). Dentre estes, os organofosforados e organoclorados apresentam grande risco à vida humana, devido a quadros de intoxicação de importância médica (Fenik et al., 2011). 
Assim, o objetivo deste trabalho é realizar uma sistematização de informações, contextualizando a problemática de forma crítica sobre os compostos organofosforados e organoclorados, com ênfase na dinâmica ambiental e seus reflexos na intoxicação humana, o diagnóstico e protocolo terapêutico, permitindo, deste modo, uma análise clara e eficiente.

\section{Metodologia}

O trabalho foi realizado por meio de uma revisão bibliográfica narrativa, delineada pela busca de artigos científicos e bibliografias com enfoque em compostos organoclorados e organofosforados, nas plataformas eletrônicas National Center for Biotechnology Information (NCBI), Scientific Eletronic Library (Scielo) e Google Acadêmico. Os descritores utilizados para busca foram: pesticidas, agrotóxicos, organoclorados, organofosforados, toxicidade, diagnóstico, tratamento e impacto ambiental, além das suas respectivas traduções para a língua inglesa. Foram utilizados métodos qualitativos, com o intuito de adquirir um apanhado atual e também robusto de dados preferencialmente descritivos, onde a análise destes, interpretação e correlação de informações seguem uma linha indutiva e crítica (Pereira et al., 2019). Os trabalhos selecionados variam do período de 1992 a 2021, de modo que os estudos que apresentavam enfoque em outros tipos de agrotóxicos, assim como não tratavam de seus efeitos tóxicos e impacto ambiental, foram descartados.

\section{Desenvolvimento}

\subsection{Organofosforados e organoclorados}

Os organofosforados são um grupo de compostos químicos derivados do ácido fosfórico. Assim, estes compostos podem ser tióis, amidas ou até mesmo ésteres de ácidos fosfônicos, fosfínicos ou tiofosfóricos. Ademais, possuem duas cadeias laterais orgânicas adicionais do grupo cianeto, tiocianato ou fenoxi, conhecidos também como colinérgicos de ação indireta ou anticolinesterásicos (Kumar et al., 2016). Alguns exemplos destes compostos são: bazudina, malatião, tiofos e metafósios (Cavalcanti et al., 2016).

Tais compostos são utilizados em grande escala, pois sofrem rápida degradação, além apresentarem amplo espectro de ação, em especial na área agrícola (Faria et al., 2007). Entretanto, estes também são tóxicos à saúde humana, de modo que a exposição prolongada a estes compostos leva a várias complicações agudas e crônicas, como prejuízo cognitivo, distúrbios neuropsiquiátricos em populações rurais e lesão aguda do miocárdio (Chen et al., 2019; Pang et al., 2019; Bojorquez-Cuevas et al., 2019).

Para mais, alguns pesticidas organofosforados acumulam-se no meio ambiente, afetando gravemente as formas de vida selvagens, como aquáticas e terrestres (Andersson et al., 2014; Sun et al., 2016; Plaza et al., 2019). Vale ressaltar que, a persistência destes compostos no ambiente depende tanto dos processos físicos quanto químicos de transformação, como lixiviação, evaporação, e absorção, assim como fatores ambientais, dentre estes a temperatura, conteúdo de matéria orgânica, acidez e umidade, além das próprias taxas de degradação das substâncias. Deste modo, pode-se dizer que há a possibilidade de interação entre todos estes processos no meio ambiente, o que, por sua vez, irá determinar o tempo de permanência de tais compostos e a velocidade de degradação (Andréa, 2004).

Como adendo, alguns compostos deste grupo pertencem às categorias dos fosfonotioatos e fosfonofluoridatos. Estes são conhecidos como agentes de guerra química, utilizados inclusive em ataques rebeldes e terroristas. Desta forma, tal aspecto também é de grande preocupação não só para a saúde dos indivíduos, como também para as demais espécies e o meio ambiente (Gupta, 2006).

Já os organoclorados são substâncias que possuem átomos de cloro covalentemente ligados em sua cadeia. Apresentam caráter altamente tóxico para o ambiente e para os indivíduos, onde os efeitos de intoxicação manifestam-se lentamente pelo 
organismo. Outro ponto importante é que, estes apresentam grande capacidade de acúmulo no decorrer da cadeia alimentar (Bai et al., 2015; Ahmed et al., 2015). Desta forma, os impactos ambientais, humanos e de vida selvagem de seus resíduos já foram detectados e relatados em diversos países (Kumar et al., 2011; Andersson et al., 2014; Sun et al., 2016).

Além disso, são insolúveis em água, bem como apresentam potencial cancerígeno (Rocha \& Spinosa, 1992). No grupo dos organoclorados, estão incluídos: DDT (dicloro-difenil-tricloroetano), BHC (hexaclorobenzeno), Aldrin, Dieldrin e Dioxina, sendo o último considerado como um dos compostos mais tóxicos já produzidos. Tais compostos são responsáveis pelo desenvolvimento porfirias, lesões hepáticas, teratogênese, imunossupressões, desregulação endócrina e carcinogênese em todos os organismos vivos (Li et al., 2012; Ge et al., 2013; Ródio et al., 2021). Consequentemente, estes foram proibidos em inúmeros países, incluindo o Brasil, embora tenham o uso permitido para o controle de vetores transmissores de doenças (Rocha \& Spinosa, 1992).

Ademais, muitos compostos organoclorados provenientes de fontes agrícolas e industriais apresentam grande resistência à degradação química e biológica. Tal fato ocorre, pois, estas substâncias possuem um alto peso molecular, bem como halogênios e/ou anéis aromáticos condensados em sua composição, além do caráter altamente lipofílico (Villaça et al., 2017). Assim, a associação entre a baixa solubilidade em água e a alta capacidade absortiva em matéria orgânica, promove a deposição e acúmulo destes compostos ao longo da cadeia alimentar, respectivamente nos tecidos com alta concentração lipídica, onde tais fatos estão relacionados a organismos vivos variados. Logo, os efeitos dos compostos organofosforados e organoclorados ao longo do tempo representam um grande risco para a saúde pública, sendo necessário o monitoramento e a vigilância desses produtos em alimentos, água, solo e até mesmo no ar.

\subsection{Epidemiologia e vias de intoxicação por organofosforados e clorados}

Apesar do potencial altamente tóxico, os compostos organofosforados e organoclorados continuam sendo utilizados de forma ampla em países com baixo índice de desenvolvimento humano, como Quênia e Índia (Sun et al., 2016; Kumar et al., 2016). Tais substâncias estão principalmente associadas a acidentes ocupacionais, entretanto, estes também são utilizados em tentativas de suicídio (Cavalcanti et al., 2016). No âmbito global, o uso de pesticidas para envenenamento intencional ocasionou aproximadamente 110.000 mortes anuais entre os anos de 2010 e 2014, valor este que representa 13,7\% dos suicídios a nível mundial (Mew et al., 2017).

Por sua vez, no Brasil, o Ministério da Saúde registrou em torno de 62 mil casos de intoxicação por organofosforados entre os anos de 1999 e 2009, resultando na estratificação de 5.600 casos por ano e um número aproximado de 1870 óbitos. Geograficamente, as áreas mais afetadas são as regiões Sudeste e Sul do país, conforme ilustrado na Figura 1 (Cavalcanti et al., 2016). 
Figura 1: Esquema com regiões mais afetadas por intoxicação envolvendo organofosforados em território brasileiro.

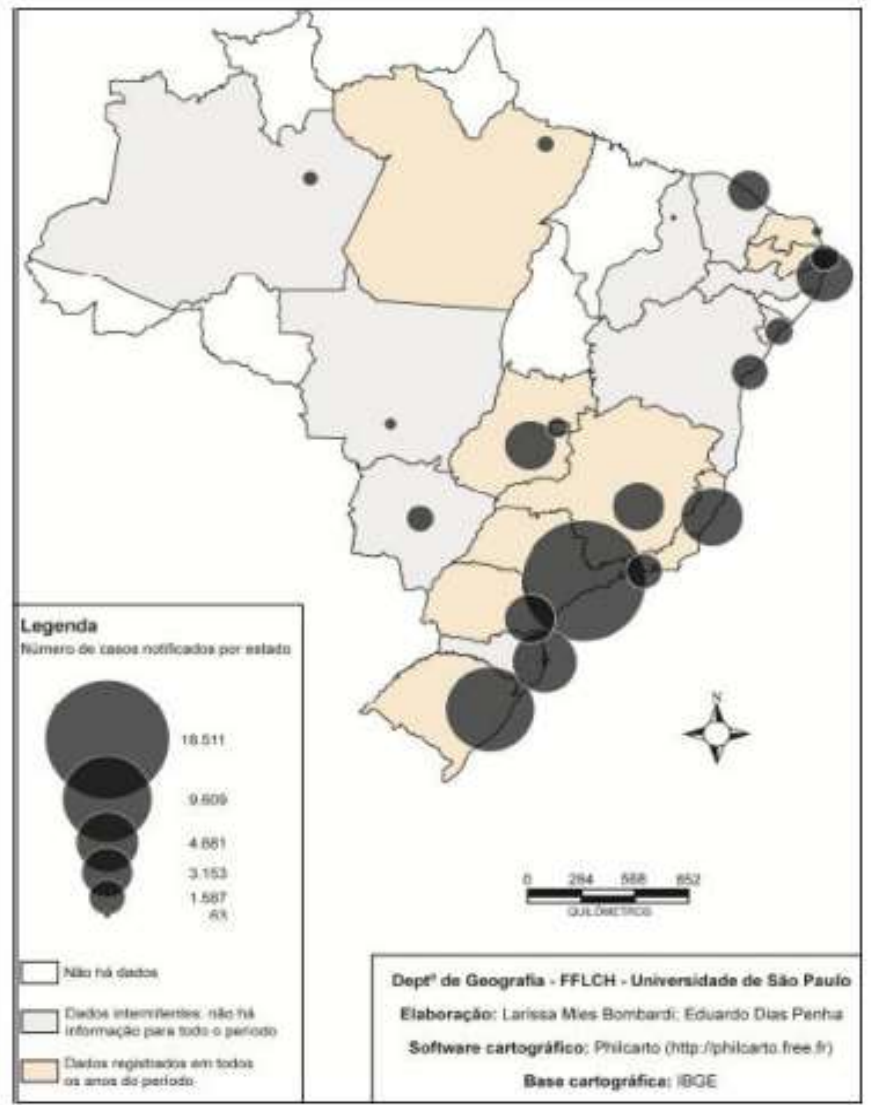

Fonte: Cavalcanti et al., (2016).

Estas substâncias podem ser absorvidas facilmente pelas vias cutânea, digestiva ou respiratória, distribuindo-se pelo organismo. Nos casos de ingestão acidental, as vias de maior relevância são a cutânea e respiratória, contudo, em tentativas de suicídio a via de maior importância é a via digestiva (Cavalcanti et al., 2016). Grande parte dos compostos organofosforados não possui atividade tóxica em sua forma original, mas os mesmos passam por uma etapa de biotransformação em organismos vivos, tornando-se metabólicos tóxicos. É de grande relevância destacar que, a alteração destes compostos também pode ocorrer pelo processo designado de metabolismo ambiental, envolvendo reações químicas e processos físicos. Logo, estes podem se acumular na água e em produtos alimentícios por longos períodos de forma sucessiva, sendo transpassados pela cadeia alimentar. Desta forma, tais compostos tendem a se concentrar no organismo humano e assim, afetando a saúde da população (Mostafalou \& Abdollahi, 2017; Sagiv et al., 2019). Tal processo ocorre por meio da oxidação de radicais associados à cadeia carbônica principal, como o grupo enxofre, tio éter, amidas, e hidroxilação de grupos alquis (Jokanovic, 2001).

Sendo assim, após a biotransformação ou metabolismo ambiental de tais compostos, quando absorvidos em altas concentrações, depositam-se principalmente em órgãos como o fígado e rins, além de possuírem a capacidade de atravessar membranas biológicas, como a barreira hematoencefálica, causando danos consideráveis ao sistema nervoso central (Cavalcanti et al., 2016). Além disso, o desenvolvimento de intoxicação e sua intensidade pode ser influenciada por outros aspectos pessoais, dentre estes o tabagismo, etilismo, estado nutricional, capacidade física e, também características ambientais, como o clima. Este último pode-se considerar como exemplo a alta temperatura, aumentando a pressão/volatilidade de vapores químicos no ambiente, e a velocidade de circulação sanguínea, impactando diretamente na disseminação dos compostos pelo organismo (Ródio et al., 2021). Outro ponto de grande importância é que, os organofosforados possuem a característica principal de inibição 
da enzima acetil-colinesterase e interação com outras biomoléculas, de maneira que o quadro de toxicidade desenvolvido pelos compostos em questão pode ser dividido em duas categorias, respectivamente: efeitos colinérgicos e não colinérgicos.

\subsection{Toxicodinâmica de organofosforados}

Os organofosforados atuam a partir da inibição de enzimas esterases, especialmente através da ligação estabelecida à acetil-colinesterase, onde esta interação pode comprometer tais enzimas de forma irreversível (Caldas, 2000). A acetil-colina comunica-se com os receptores de acetil-colina, apresentando um papel de suma importância na regulação da frequência cardíaca, contração dos músculos lisos, atividade secretória por glândulas e outras funções do sistema nervoso central, através das vias de sinalização por proteína G (Picciotto et al., 2012; Kruse et al., 2014). Contudo, o neurotransmissor em questão também interage com receptores nicotínicos, auxiliando, desta forma, no processo cognitivo (Dani, 2015; Nishio et al., 2015).

Em uma situação de homeostase, após a sinalização neural a acetil-colina é degradada pela acetil-colinesterase em acetato e colina. Todavia, quando tal atividade é inibida, gera-se o quadro designado como efeito colinérgico excessivo, uma vez que não há a finalização da transmissão dos impulsos nervosos, pelo acúmulo de acetil-colina nas fendas sinápticas. Sendo assim, é desenvolvida uma hiper-estimulação dos receptores colinérgicos no sistema nervoso central, junções neuromusculares, terminais pós-ganglionares parassimpáticos na musculatura lisa, cardíaca, glândulas e também no sistema nervoso autônomo, podendo inclusive culminar em óbito (Curtil \& Masson, 1993; Caldas, 2000). Logo, o estímulo ocorrente é exacerbado em todos os receptores colinérgicos muscarínicos e nicotínicos, pela quantidade excessiva de acetil-colina não degradada pela sua respectiva esterase (Caldas, 2000).

Neste cenário, com a retirada de um grupo funcional dos compostos ou da própria enzima, como a perda de grupamentos alquilas pelas esterases, pode-se desenvolver uma interação mais intensa e permanente entre os organofosforados e a acetilcolinesterase. Observa-se assim em um estado irreversível de inativação enzimática, denominado de envelhecimento da enzima (Curtil \& Masson, 1993). É de grande relevância enfatizar também que, a estereoquímica dos compostos também é um ponto de influência no que diz respeito ao quadro de reativação enzimática (Cheung et al., 2018). Os sinais e sintomas comumente presentes nestes casos se desenvolvem devido à combinação dos efeitos de estimulação nicotínica central, muscarínica e/ou estão associados à paralisia de receptores, como: diarreia, bradicardia, salivação e hipotensão, podendo ainda haver alteração do nível de consciência e tremores, que são ocasionados principalmente por conta da crise colinérgica aguda (Solomon et al., 2007; Cavalcanti et al., 2016).

Ademais, as manifestações clínicas podem se apresentar nos indivíduos de formas variadas conforme a Figura 2, havendo relação com as propriedades físico-químicas do composto, a via de intoxicação, bem como o a quantidade e o tempo de exposição (Caldas, 2000). 
Figura 2: Sinais e sintomas de intoxicação por organofosforados e carbamatos.

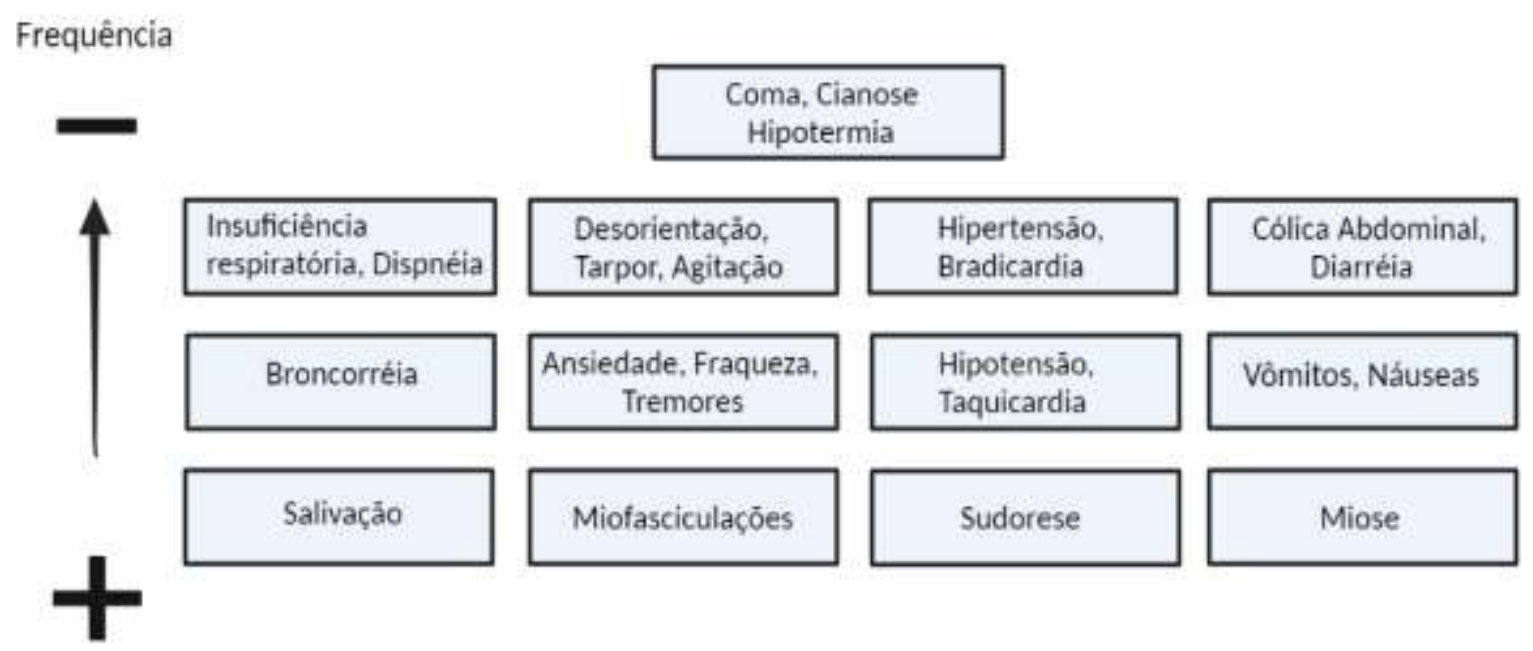

Fonte: Modificada e adaptada de: Caldas (2000).

Os compostos organofosforados também podem causar outra neurotoxicidade, conhecida como polineuropatia retardada induzida, tendo como principais sintomas o formigamento das mãos e pés, perda sensorial, fraqueza muscular seguida por flacidez dos músculos esqueléticos distais e ataxia. Estes sintomas são causados pela inibição das atividades que envolvem as enzimas esterases e fosfolipases (Lotti \& Moretto, 2005; Nand et al., 2007).

Outro aspecto já relatado é que, fora a inibição da esterase, os organofosforados também demonstraram potencial inibitório de inúmeras lipases, e de acil-peptídeo-hidrolase, uma peptidase presente em roedores, de forma que tais compostos também estão associados ao estresse oxidativo, relatado em diversos modelos in vitro e in vivo, assim como em estudos humanos (Richards et al., 2000; Kovacic, 2003; Quistad et al., 2006; Giordano et al., 2007).

\subsection{Toxicologia dos organoclorados}

A intoxicação com organoclorados, em sua maioria, ocorre de forma acidental, podendo ocorrer pelo derramamento de inseticidas armazenados junto dos alimentos, por pulverização, contaminação da água, por via respiratória ou em contato com a pele. Outro aspecto potencializante relacionado ao quadro de intoxicação é que os compostos organoclorados atravessam as membranas biológicas, inclusive a barreira hematoencefálica, com grande facilidade, sendo transportados para diversas regiões do organismo através da circulação sanguínea, causando por sua vez grande impacto ao sistema nervoso central (Solomon et al., 2007; Villaça et al., 2017).

Tais compostos ainda apresentam a característica de permanecer no organismo por longos períodos, pois são lipossolúveis, sendo assim absorvidos e "estocados" no tecido adiposo, além de serem passíveis de transferência para o leite materno, havendo chances de intoxicação de lactentes. Ademais, modelos roedores já demonstraram que estas substâncias geram impactos neurocomportamentais, a partir de reduções significativas na expressão gênica para receptores colinérgicos muscarínicos, assim como alterações neuroquímicas (Villaça et al., 2017).

Mesmo possuindo capacidade tóxica elevada, estes continuam sendo a primeira escolha como forma de controle vetorial, em regiões fortemente acometidas por malária e por febre amarela (Fernandes et al., 2020). Logo, seus impactos neurotóxicos nestes locais são preocupantes. A geração de neurotoxicidade ocorre, pois, a grande maioria dos organoclorados não é específica para o controle de um respectivo inseto, implicando principalmente no sistema nervoso central dos mesmos. 
Ademais, por haver certa proximidade entre os neurotransmissores de mamíferos e destes organismos vivos, seus efeitos neurotóxicos podem acometer os seres humanos de forma grave (Villaça et al., 2017).

Deste modo, os efeitos dos organoclorados no sistema nervoso central humano são decorrentes do estímulo inespecífico sobre os neurônios e a atividade neuronal. Ao atravessar a membrana axonal, tais compostos interferem na transmissão dos impulsos nervosos, devido ao fechamento lento dos canais iônicos de sódio. Tal fato impede a saída de íons potássio e consequentemente provoca a redução do limiar de membrana, gerando por sua vez a sintomatologia aguda de estímulo no sistema nervoso central (Srivastava et al., 1995; Solomon et al., 2007; Villaça et al., 2017).

Em casos exposição constante e de cronicidade, pode haver o comprometimento múltiplo do organismo, como lesões no miocárdio, degenerações hepáticas e até mesmo renais, já que estes dois últimos são responsáveis pelas atividades de metabolização e excreção, onde já foram descritas também alterações nos sistemas reprodutor, respiratório, circulatório e imunológico (Srivastava et al., 1995).

Os sinais clínicos de intoxicação por organoclorados são semelhantes em seres humanos e outros mamíferos, sendo frequentes os sinais neurológicos agudos, como alterações comportamentais, parestesia da língua, lábios, seguida pelos membros, fotofobia, ataxia, convulsões, coma e morte. Como adendo, outras alterações podem ser manifestadas, havendo variação conforme a via de intoxicação, como vômitos e diarreia por via oral; rinorréia, tosse, bradipinéia e broncopneumonia grave por inalação; e desenvolvimento de dermatites em casos de contato com a pele (Hatch, 1992).

\subsection{Diagnóstico e protocolo terapêutico}

O diagnóstico de quadros que envolvem intoxicação por tais pesticidas é majoritariamente clínico. Devem ser observados sinais e sintomas, além da correlação com o histórico do paciente. Isto por sua vez, inclui inúmeros aspectos, como o local onde este reside, rotina diária, alimentação, e profissão exercida. Neste cenário, o prognóstico acaba por ser mais favorável quando o diagnóstico é realizado de maneira rápida. Assim, é importante a identificação do agente tóxico, da via de exposição, do período de tempo entre a exposição e início do atendimento e da quantidade absorvida estimada (Roberts \& Reigart, 2013).

Ademais, análises laboratoriais para avaliação/diagnóstico de intoxicação podem ser realizadas. A determinação de atividade da colinesterase eritrocitária (AChE) e colinesterase plasmática (BChE) é o principal marcador a ser considerado. Essas dosagens podem ser utilizadas principalmente nos quadros de intoxicação crônica, podendo auxiliar inclusive na caracterização do prognóstico e evolução do paciente (Lionetto et al., 2013; Pearson et al., 2017).

Outros exames podem ser utilizados para análise e elucidação do caso se necessários, entre eles hemograma, ionograma (quantificação de eletrólitos), marcadores da função hepática, marcadores cardíacos e gasometria (Hernández et al., 2006; Shadnia et al., 2009; Laudari et al., 2014; Sun et al., 2015). Este último, deve-se atentar para as possíveis alterações de $\mathrm{HCO}_{3}$.

O protocolo terapêutico seguido em casos de intoxicação aguda por compostos organofosforados consiste principalmente na administração de carvão ativado, do agente antimuscarínico atropina, oximas, drogas anticonvulsivantes/neuroprotetoras e cuidados intensivos quando necessários (Bucaretchi \& Baracat, 2005; Cavalcanti et al., 2016; Hulse et al., 2019). O uso de atropina é realizado para a interrupção do efeito colinesterásico proveniente da toxicidade, enquanto a administração de oximas apresenta como ponto principal a reativação da enzima acetil-colinesterase, através da remoção do grupo fosforil da mesma e assim permitindo a restauração da transmissão neuromuscular nas sinapses nicotínicas (Cavalcanti et al., 2016; Hulse et al., 2019). Porém, é importante ressaltar que a capacidade de reativação da enzima inibida é variável, o que acaba por promover os diferentes níveis de toxicidade manifestados, além do que, tal estratégia não é eficiente para todos os organofosforados, tendo como exemplo alguns gases utilizados para guerra ou inseticidas (Cavalcanti et al., 2016).

Fora estas estratégias, atualmente, vem sendo discutida a terapêutica envolvendo o uso de bioscavengers. Estes são enzimas, que podem ser estequiométricas, catalíticas de origem bacteriana ou animal, ou pseudocatalíticas, de modo que estas 
podem ser manipuladas em ambiente laboratorial, para casos agudos e crônicos de intoxicação. Assim, apresentam caráter inativador, hidrolítico não tóxico ou reativador da enzima inibida associado à oximas. A administração pode ser feita por via intravenosa, intramuscular ou por aerossol, e os efeitos propostos já foram relatados em macacos (Doctor \& Saxena, 2005; Mao et al., 2013; Hernandez-Abanto et al., 2015; Lushchekina et al., 2018).

Deste modo, o uso de bioscavengers possui como ponto chave a hidrólise do composto responsável pela toxicidade, a interação com a substância e inativação da mesma, ou até mesmo de reativação enzimática previamente inibida. Contudo, os organofosforados são substratos não fisiológicos, além do que, estes compostos naturalmente são quirais, estando presentes em suas diferentes formas enantioméricas, tornando a eficiência enzimática inadequada e limitada, devido às características de estereoseletividade (Doctor \& Saxena, 2005; Masson \& Lushchekina, 2016; Lushchekina et al., 2018).

Em contrapartida, não há nenhuma descrição de tratamento/manejo definitivo em casos de toxicidade por organoclorados, havendo assim a opção de cuidados paliativos para a minimização das manifestações clínicas apresentadas.

\section{Conclusão}

Os compostos organofosforados e organoclorados estão principalmente associados a acidentes ocupacionais, podendo se apresentar de forma leve ou grave, além de estarem também relacionados a quadros de suicídio. Logo, quando absorvidos em altas concentrações, podem causar danos relevantes ao sistema nervoso central de forma irreversível, ocasionando em óbito. Entretanto, mesmo apresentando potencial tóxico ao ambiente e às formas de vida presentes, os compostos organofosforados continuam sendo amplamente utilizados no controle de pragas agrícolas, enquanto os organoclorados, para o controle vetorial e transmissão de doenças, como regiões acometidas por malária e febre amarela. Assim, é nítido que o uso contínuo e inadequado de pesticidas afeta todo o ambiente, levando à contaminação da água e do solo, impactando diretamente os biomas e ecossistemas das regiões acometidas. Para mais, o uso de agrotóxicos também impacta na cadeia alimentar, uma vez que, tais substâncias são passíveis de acúmulo no organismo, chegando por fim ao ser humano.

Vale ressaltar que, em face aos riscos do uso destes compostos, novos trabalhos envolvendo a temática podem contribuir para a investigação, diagnóstico e manejo dos casos de intoxicação de maneira mais eficaz. Como adendo, uma legislação e fiscalizações mais rigorosas, assim como políticas públicas de educação sobre o assunto podem ser de grande auxílio.

\section{Referências}

Ahmed, G., Anawar, H. M., Takuwa, D. T., Chibua, I. T., Singh, G. S. \& Sichilongo, K. (2015). Environmental assessment of fate, transport and persistent behavior of dichlorodiphenyltrichloroethanes and hexachlorocyclohexanes in land and water ecosystems. Int. J. Environ. Sci. Technol, 12, 2741-2756.

Andersson, H., Tago, D. \& Treich, N. (2014). Pesticides and health: A review of evidence on health effects, valuation of risks, and benefit-cost analysis. In Preference Measurement in Health: Emerald Group Publishing Limited, 24, 203-295. Bingley. UK.

Andréa, M.M. (2004). Contaminação do solo por pesticidas. Centro de Proteção Ambiental do Instituto Biológico.

Bai, J., Lu, Q., Zhao, Q., Wang, J., Gao, Z. \& Zhang, G. (2015). Organochlorine pesticides (OCPs) in wetland soils under different land uses along a 100-year chronosequence of reclamation in a Chinese estuary. Sci. Rep, 5:17624. http//dx.doi.org/10.1038/srep17624.

Baptista, G. C. (1999). Desenvolvimento do uso de pesticidas! inseticidas. Manual de resíduos de pesticidas em alimentos. GARP-Associação Grupo de Analistas de Resíduos de Pesticidas.

Bester, S. M., Guelta, M. A., Cheung, J., et al. (2018). Structural insights of stereospecific inhibition of human acetylcholinesterase by VX and subsequent reactivation by HI-6. Chemical Research in Toxicology, 31(12), 1405-1417.

Botelho, M. G. L., Pimentel, B. S., Furtado, L. G., Lima, M. C. S., et al. (2020). Agrotóxicos na agricultura: agentes de danos ambientais e a busca pela agricultura sustentável. Research, Society and Development, 9(8), e396985806. http://dx.doi.org/10.33448/rsd-v9i8.5806.

Bucaretchi, F. \& Baracat, E. C. (2005). Exposições tóxicas agudas em crianças: um panorama. J Pediatria, 81(5), $212-222$.

Caldas, L. Q. A. (2000). Intoxicações exógenas agudas por carbamatos, organofosforados, bipiridílicos e piretróides. Centro de Controle de Intoxicações de Niterói. Rio de Janeiro. 
Cavalcanti, L., Aguiar, A., Lima, J. \& Lima, A. (2018). Intoxicação por Organofosforados: Tratamento e Metodologias Analíticas Empregadas na Avaliação da Reativação e Inibição da Acetilcolinesterase. Rev.Virtual Qui, 8(3), 739-766.

Chen K. X., Zhou, X. H., Sun, C. A. \& Yan, P. X. (2019). Manifestations of and risk factors for acute myocardial injury after acute organophosphorus pesticide poisoning. Medicine (Baltimore), 98(6), e14371. http://dx.doi.org/10.1097/MD.0000000000014371.

Curtil, C. \& Masson, P. (1993). Aging of cholinesterase after inhibition by organophosphates. Annales Pharmaceutiques Françaises, 51 (2), 63-77.

Dani, J. A. (2015). Neuronal nicotinic acetylcholine receptor structure and function and response to nicotine. International Review of Neurobiology, 124, 3-19. 10.1016/bs.irn.2015.07.001

Doctor, B. P. \& Saxena, A. (2005). Bioscavengers for the protection of humans against organophosphate toxicity. Chemico-Biological Interactions, 157-158, 167-171.

Faria, N. M. X., Fassa, A. G. F. \& Facchini, L. A. (2007). Intoxicação por agrotóxicos no Brasil: os sistemas oficiais de informação e desafios para realização de estudos epidemiológicos. Ciências e Saúde Coletiva, 12(1), 25-38.

Fenik, J., et al. (2011). Properties and determination of pesticides in fruits and vegetables. Trac Trends in Analytical Chemistry, 30(6). http://dx.doi.org/10.1016/j.trac.2011.02.008

Fernandes, C. L. F., Ramires, P. F., Moura, R. R., Pohren, R. S., et al. (2020). Quais agrotóxicos estão contaminando os solos brasileiros? Research, Society and Developement, 9(3), e114932569. http://dx.doi.org/10.33448/rsd-v9i3.2569.

Ge, J., Woodward, L. A., Li, Q. X. \& Wang, J. (2013). Composition, distribution and risk assessment of organochlorine pesticides in soils from the Midway Atoll. North Pacific Ocean. Sci. Total Environ, 452-453, 421-426. https://doi.org/10.1016/j.scitotenv.2013.03.015.

Giordano, G., Afsharinejad, Z., Guizzetti, M., Vitalone, A., Kavanagh T. J. \& Costa, L. G. (2007). Organophosphorus insecticides chlorpyrifos and diazinon and oxidative stress in neuronal cells in a genetic model of glutathione deficiency. Toxicology and Applied Pharmacology, 219(2-3), 181-189. https://doi.org/10.1016/j.taap.2006.09.016.

Gupta, R. C. (2006). Classification and uses of organophosphates and carbamates. Elsevier, 5-24. Amsterdam. Netherlands. https://doi.org/10.1016/B978012088523-7/50003-X.

Hatch, R. Venenos causadores de insuficiência respiratória. (1992). In: Booth, N. H. \& McDonald, L. E. Farmacologia e terapêutica em veterinária. (6a ed). Rio de Janeiro. Guanabara-Koogan.

Hernández, A. F., Amparo, M. G., Pérez, V., García-Lario, J. V., Pena, G., Gil, F., et al. (2006). Influence of exposure to pesticides on serum components and enzyme activities of cytotoxicity among intensive agriculture farmers. Environ Res, 102(1), 70-76. https://doi.org/10.1016/j.envres.2006.03.002.

Hulse, E. J., Haslam, J. D., Emmett, S. R. \& Woolley, T. (2019). Organophosphorus nerve agent poisoning: managing the poisoned patient. British Journal of Anaesthesia, 123(4), 457-463. http//doi.org/10.1016/j.bja.2019.04.061.

Jokanovic, M. (2001). Biotransformation of organophosphorus compounds. Toxicology, 166(3), 139-160.

Kovacic, P. (2003). Mechanism of organophosphates (nerve gases and pesticides) and antidotes: electron transfer and oxidative stress. Current Medicinal Chemistry, 10(4), 2705-2709.

Kruse, A. C., Kobilka, B. K., Gautam, D., Sexton, P. M., Christopoulos, A. \& Wess, J. (2014). Muscarinic acetylcholine receptors: novel opportunities for drug development. Nature Reviews Drug Discovery, 13(7), 549-560.

Kumar, B.; Kumar, S.; Gaur, R.; Goel, G.; Mishra, M.; Singh, S. K.; Prakash, D.; Sharma, C.S. (2011). Persistent organochlorine pesticides and polychlorinated biphenyls in intensive agricultural soils from North India. Soil Water Res, 6(4), 190-197.

Kumar, S., Kaushik, G., Villarreal-Chiu, J. F. (2016). Scenario of organophosphate pollution and toxicity in India: a review. Environmental Science and Pollution Research, 23(10), 9480-9491.

Laudari, S., et al. (2014). Cardiovascular Effects of Acute Organophosphate Poisoning. Asia Pac J Med Toxicol, 3(2), 64-67.

Li, W., Yang, H., Gao, Q., Pan, H. \& Yang, H. (2012). Residues of organochlorine pesticides in water and suspended particulate matter from Xiangshan Bay, East China Sea. Bull. Environ. Contam. Toxicol, 89, 811-815.

Lionetto, M. G., Caricato, R., Calisi, A., Giordano, M. E. \& Schettino, T. (2013). Acetylcholinesterase as a biomarker in environmental and occupational medicine: new insights and future perspectives. BioMed Res International, 2013. http://dx.doi.org/10.1155/2013/321213.

Lotti, M. \& Moretto, A. (2005). Organophosphate-induced delayed polyneuropathy. Toxicological Reviews, 24(1), 37-49.

Lushchekina, S.V., Schopfer, L.M. \& Grigorenko, B. L. (2018). Optimization of cholinesterase-based catalytic bioscavengers against organophosphorus agents. Frontiers in Pharmacology, 9, 211.

Masson, P. \& Lushchekina, S. V. (2016). Emergence of catalytic bioscavengers against organophosphorus agentes. ChemicoBiological Interactions, 259, 319326.

Mew, E. J., Padmanathan, P., Konradsen, F., et al. (2017). A global burden of fatal self-poisoning with pesticides 2006-15: systematic review. Journal of Affective Disorders, 219, 93-104. 
Mine, N., Taniguchi, W., Nishio, N., et al. (2015). Synaptic modulation of excitatory synaptic transmission by nicotinic acetylcholine receptors in spinal ventral horn neurons. Neuroscience, 290, 18-30. https://doi.org/10.1016/j.neuroscience.2015.01.015.

Mostafalou, S. \& Abdollahi, M. (2017). Pesticides: an update of human exposure and toxicity. Arch. Toxicol, 91(2), 549-599. https://doi.org/10.1007/s00204016-1849-x.

Nand, N., Aggarwal, K., Bharti, K., \& Chakrabarti, D. (2007). Organophosphate induced delayed neuropathy JAPI, 55 , 72-73.

Oga, S. (2003). Fundamentos de Toxicologia. (2a ed). Atheneu.

Pang, L., Liu, J., Li, W., Xia, Y. \& Xing, J. (2019). Serum ubiquitin Cterminal hydrolase L1 predicts cognitive impairment in patients with acute organophosphorus pesticide poisoning. Journal of Clinical Laboratory Analysis, 33(7), e22947.

Pearson, M., Metcalfe, C., Jayamanne, S., Gunnell, D., Weerasinghe, M., Pieris, R., et al. (2017). Effectiveness of household lockable pesticide storage to reduce pesticide self-poisoning in rural Asia: a community-based, cluster-randomised controlled trial. Lancet (London, England), 390, $1863-1872$.

Pereira, A. S., et al. (2018). Metodologia da pesquisa científica. UFSM..

Picciotto, M. R., Higley, M. J. \& Mineur, Y. S. (2012). Acetylcholine as a neuromodulator: cholinergic signaling shapes nervous system function and behavior. Neuron, 76(1), 116-129. http://dx.doi.org/10.1016/j.neuron.2012.08.036.

Plaza, P. I., Martínez-Lopez, E. \& Lambertucci, S. A. (2019). Perfect threat: pesticides and vultures. Science Of The Total Environment, 687, $1207-1218$.

Quistad, G. B., Liang, S. N., Fisher, K. J., Nomura, D. K. \& Casida, J. E. (2006). Each lipase has a unique sensitivity profile for organophosphorus inhibitors. Toxicological Sciences, 91(1), 166-172. http://dx.doi.org/10.1093/toxsci/kfj124.

Richards, P. G., Johnson, M. K. \& Ray, D. E. (2000). Identification of acylpeptide hydrolase as a sensitive site for reaction with organophosphorus compounds and a potential target for cognitive enhancing drugs. Molecular Pharmacology, 58(3), 577-583. https://doi.org/10.1124/mol.58.3.577.

Rocha, L. C. S. \& Spinosa, H. S. (1992). Praguicidas organofosforados e carbamatos: algumas considerações. Comunicações Científicas da Faculdade de Medicina Veterinária e Zootecnia da Universidade de São Paulo, 16.

Ródio, G. R., Rosset, I. G. \& Brandalize, A. P. C. (2021). Exposição a agrotóxicos e suas consequências para a saúde humana. Research, Society and Developement, 10(8), e43010817526. http://dx.doi.org/10.33448/rsd-v10i8.17526.

Rosemberg, Y. J., Laube, B., Mao, L., et al. (2013). Pulmonary delivery of an aerosolized recombinant human butyrylcholinesterase pretreatment protects against aerosolized paraoxon in macaques. Chemico-Biological Interactions, 203(1), 167-171.

Rosemberg, Y. J., Adams, R. J., Hernández-Abanto, S., et al. (2015). Pharmacokinetics and immunogenicity of a recombinant human butyrylcholinesterase bioscavenger in macaques following intravenous and pulmonary delivery. ChemicoBiological Interactions, 242, $219-226$.

Roberts, J. R. \& Reigart, J. R. (2013). Recognition and Management of Nonrelaxing. (6a ed). United States. Environmental Protection Agency.

Sagiv, S. K., Bruno, J. L., Baker, J. M., Palzes, V., Kogut, K., Rauch, S., Gunier, R., et al. (2019). Prenatal exposure to organophosphate pesticides and functional neuroimaging in adolescents living in proximity to pesticide application. Proc. Natl. Acad. Sci, 116(37), 18347-18356. Uni States Am.

Santos, S. P. D. (2002). A Química dos Insecticidas (Parte I). Boletim da Sociedade Portuguesa de Química, 85.

Serrano-Medina, A., Ugalde-Lizárraga, A., Bojorquez-Cuevas, M., et al. (2019). Neuropsychiatric disorders in farmers associated with organophosphorus pesticide exposure in a rural village of northwest Mexico. International Journal of Environmental Research and Public Health, $16(5), 689$.

Shadnia, S., Okazi, A., Akhlaghi, N., Sasanian, G. \& Abdollahi, M. (2009). Prognostic value of long QT interval in acute and severe organophosphate poisoning. J Med Toxicol, 5(4), 196-199.

Solomon, C., Poole, J., Palmer, K. T., Peveler, R. \& Coggon, D. (2007). Acute symptoms following work with pesticides. Occupational Medicine, 54(10), 665670 .

Srivastava, A. K., et al. (1995). Chronic effects of hexachlorociclohexane exposure: clinicai, hematologic and electrographic studies. Veterinary and Humall Toxicology, 37(4), 302-305.

Sun, H., Qi, Y., Zhang, D., Li, Q. X. \& Wang, J. (2016). Concentrations, distribution, sources and risk assessment of organohalogenated contaminants in soils from Kenya, Eastern Africa. Environ. Pollut, 209, 177-185. https://doi.org/10.1016/j.envpol.2015.11.040.

Sun, I. O., Yoon, H.J. \& Lee, K. Y. (2015). Prognostic Factors in Cholinesterase Inhibitor Poisoning. Med Sci Monit, 33(3), 534-539.

Teixeira, H., et al. (2004). Pesticide intoxications in the Centre of Portugal: Three years analysis. Forensic Science International, 143(2-3), 199-204. https://doi.org/10.1016/j.forsciint.2004.02.037.

Villaça, Y. \& Levin, E. (2018). Developmental neurotoxicity of succeeding generations of insecticides. Elsevier, 99, 55-77. https://doi.org/10.1016/j.envint.2016.11.019. 